\title{
STORE ATMOSPHERE DAN GAYA HIDUP HEDONIS SEBAGAI PENENTU KEPUTUSAN PEMBELIAN (STUDI PADA KONSUMEN ROLAG KOPI KAYOON SURABAYA)
}

\author{
Kartika Ayu Wulandari \\ Universitas Negeri Surabaya \\ kartikawulandari@mhs.unesa.ac.id \\ Sri Setyo Iriani \\ Universitas Negeri Surabaya \\ srisetyo@unesa.ac.id
}

Abstract

\begin{abstract}
The potential of café and restaurant business in East Java is on the rise and remains enormous enough to run. This has triggered intense competition among café business owners in Surabaya. Currently, there has been a change in lifestyle during society. People (specifically teenagers) in big cities prefer to spend their leisure to relax in the cafe. Many cafes have sprung up with distinguishing concepts to attract consumers. Rolag Kopi Kayoon Surabaya is one of the cafes that has carried out a marketing strategy by creating a different store atmosphere. The hedonic lifestyle of urban communities can be also one of the factors which influence the consumer purchasing decision. This study aims to analyze and discuss the effect of store atmosphere and hedonic lifestyle on purchasing decisions on consumers Rolag Kopi Kayoon Surabaya. This research was conducted at Rolag Kopi Kayoon Surabaya by using data of a questionnaire of 110 respondents with a minimum age of 17 years old. The sampling method used is a judgmental sampling. The measurement scale applied is the Likert scale. The statistical analysis used is multiple linear regression equation models. The results showed that the store atmosphere and hedonic lifestyle variables significantly and positively influenced purchasing decisions. The biggest influence on purchasing decisions is the store atmosphere with a level of influence at $20.7 \%$.
\end{abstract}

Keywords: hedonic lifestyle; lifestyle; purchasing decisions; store atmosphere.

\section{PENDAHULUAN}

Perkembangan bisnis café dan restoran di Jawa Timur masih sangat besar, salah satunya di kota Surabaya. Berdasarkan pernyataan Asosiasi Pengusaha Kafe dan Restoran Indonesia (Apkrindo), usaha cafe dan restoran di Surabaya mengalami pertumbuhan hingga 20\% setiap tahunnya. Meski kondisi ekonomi pada semester pertama dinilai kurang bergairah, tapi minat wirausaha sektor kuliner di Surabaya masih tinggi (Peni, 2019). Pemasar harus bisa memahami perilaku konsumen yang terus berubah, sehingga bisa menetukan strategi yang tepat hal tersbut akan menjadi kunci kesuksesan utama bagi pemasar (Sunarto,2018). Tidak menutup kemungkinan pasar akan jenuh sehingga berdampak pada eksistensi bisnis café itu sendiri (Peni, 2019).

Perilaku konsumen akan menentukan proses pengambilan keputusan seseorang dalam membeli. Perilaku konsumen merupakan suatu kegiatan individu yang secara langsung terlibat dalam mendapatkan dan mempergunakan barang atau jasa termasuk didalamnya proses pengambilan keputusan yang mendahului dan mengikutinya (Engel, et,al, 1995:3). Menurut Kotler dan Keller (2012:151) menyatakan bahwa ada beberapa faktor yang memengaruhi perilaku konsumen di antaranya, faktor internal berupa karakteristik konsumen yang terdiri dari faktor pribadi (gaya hidup, pekerjaan, kepribadian, keadaan ekonomi, usia dan tahap siklus hidup), faktor sosial, faktor psikologi dan faktor kebudayaan. Selain itu juga terdapat faktor eksternal, seperti stimuli pemasaran atau sering disebut dengan marketing mix (bauran pemasaran).

Saat ini, banyak café memiliki keunikan yang berbeda-beda untuk menarik konsumen. Bervariasinya konsep cafe di Surabaya membuat konsumen lebih selektif melakukan pemilihan atas cafe yang akan dikunjungi (Vicky, 2019). Mulai dari menawarkan konsep unik, tambahan layanan seperti wifi atau 
Kartika Ayu Wulandari \& Sri Setyo Iriani. Store Atmosphere dan Gaya Hidup Hedonis sebagai Penentu Keputusan Pembelian (Studi pada Konsumen Rolag Kopi Kayoon Surabaya)

live musik, produk yang ditawarkan, bahkah promo disetiap event tertentu (Utami, 2018). Menurut Foster (2008; dalam Hidayat,. et, al, 2018),bahwa store atmosphere adalah efek emosional yang ditimbulkan dari adanya perubahan perencanaan lingkungan yang dapat mengakibatkan seseorang melakukan tindakan pembelian. Sementara Utami (2012:279), menyatakan store atmosphere adalah proses menciptakan suasana merupakan rancangan lingkungan gerai melalui visual, suara, perwarnaan, pengaturan cahaya dan aroma untuk merangsang respon emosi dan persepsi konsumen sehingga memengaruhi tindakannya dalam membeli barang. Berdasarkan penelitian yang dilakukan oleh Vicky (2019) Store atmosphere berpengaruh signifikan terhadap keputusan pembelian pada café Calibre. Semakin menarik atmosfer yang disajikan maka konsumen akan betah dan nyaman berada di Café, sehingga kemungkinan besar pembelian akan semakin meningkat. Hal tersebut juga didukung dengan penelitian yang dilakukan Purnomo (2017), peran cafe astmosphere mampu merangsang keputusan pembelian pelanggan, mampu memengaruhi stimulus positif melalui kondisi eksterior dan store layout, dengan memperhatikan tata ruang dan jarak antar meja.

Selain faktor eksternal yaitu store atmosphere terdapat faktor lain yang berasal dari internal, yakni gaya hidup. Gaya hidup didefinisikan sebagai cara hidup individu bagaimana menghabiskan waktu mereka (aktivitas), apa yang dianggap penting oleh mereka dalam lingkungannya (ketertarikan/minat), apa yang dipikirkan tentang diri mereka sendiri dan juga dunia sekitarnya (pendapat) (Setiadi, 2010:77). Menurut Subandy dalam Achmad Syaiful (2012:15) ada beberapa bentuk gaya hidup, di antaranya adalah gaya hidup mandiri, gaya hidup hedonis dan gaya hidup konsumtif.

Berdasarkan penyataan Susianto (1993), Gaya hidup hedonis merupakan pola hidup yang mengarahkan aktivitasnya untuk mencari kesenangan hidup, berupa menghabiskan waktu di luar rumah, lebih banyak bermain mengarah kepada kesenangan, senang membeli barang yang kurang diperlukan dan selalu ingin menjadi pusat perhatian. Menurut Rinandiyana, et. al., (2018) membuktikan dalam penelitiannya menyatakan bahwa gaya hidup saat ini cenderung mengarah pada gaya hidup hedonis. Perilaku hedonisme sudah sangat melekat pada sebagian masyarakat Indonesia terutama di kota-kota besar, dimana gaya hidup hedonis bersifat negarif karena hanya mementingkan, kesenangan dan kepuasan yang bersifat dunawi.

Gaya hidup hedonisme ini dianggap menarik, mengingat gaya hidup hedonisme ini memiliki daya tarik yang besar terhadap kehidupan. Secara eksternal individu yang hedonis akan mengarahkan aktivitasnya pada kesenangan. Gaya hidup seperti inilah yang menjadi tujuan dari kalangan menengah keatas. Teknologi informasi telah banyak merubah gaya hidup kearah yang modern karena bukan sekedar memenuhi kebutuhan hidup melainkan keinginan untuk mencapai kepuasan. Minum kopi menjadi gaya hidup kaum millenial serta sebuah media bersosialisasi dengan teman atau lingkungan sekitar (Hafasnuddin., et, al, 2018). Sekarang ini, café tidak hanya menjadi tempat melakukan aktivitas untuk menikmati secangkir kopi, melainkan juga menjadi tempat untuk mengisi waktu luang dengan berkumpul dengan teman, ngopi di café juga sebagai tempat untuk menciptakan suasana baru diluar lingkungan kerja, tempat bagi para pebisnis mengadakan pertemuan, sebagai wadah memperluas pergaulan sosial, tempat nongkrong, tempat berkumpul dengan komunitas, dan sebagai tempat bersenang-senang untuk menghabiskan waktu luang, sehingga memunculkan gaya hidup baru (Selvi dan Ningrum, 2020). Budaya asing mengunjungi café shop memunculkan trend baru. Cafe sudah seperti surga bagi anak muda yang ada di kota Surabaya karena menggemari aktivitas nongkrong atau untuk memuaskan hasrat rasa penasaran terhadap café baru.

Rolag Kopi Kayoon merupakan salah satu café yang menyediakan kopi lokal dan telah menjalankan bisnisnya sejak tahun 2015, berlokasi di Jl. Kayoon, Surabaya dan di jalan Jl. Khairil Anwar, Darmo. Rolag Kopi yang identik dengan kesan warung kopi dengan ruangan outdoor yang sederhana, kini mulai mencoba untuk melakukan perbaikan dari segi memperhatikan suasana dan desain gerai untuk menyesuaikan pasar sasarannya. Melalui dua cabang barunya, Rolag Kopi kini merubah pasar sasarannya pada kalangan menengah keatas. Mereka lebih mempersiapkan dengan matang store atmosphere café yang lebih konseptual agar dapat menarik minat konsumen berkunjung, dari hasil wawancara dengan manajer Rolag Kopi Kayoon pada (14 November 2019). 
Berikut beberapa café asing dan lokal yang ada di sekitar Rolag Kopi Kayoon dengan store atmosphere yang berbeda-beda, sebagai berikut. Kopi Rolag cabang Kayoon, menawarkan suasana outdoor dengan pemandangan sungai dan keramaian perkotaan, fasilitas ruangan indoor dengan desain minimalis modern, ber-AC terdapat music in the store dan live band, menggunakan properti bernuansa kayu dan sofa untuk kursi, desain café bertema stasiun kereta api dengan dekorasi unik. Pencahayaan baik di indoor maupun outdoor. Area parkir cukup luas, terdapat ruang meeting, hasil dari observasi lokasi pada (22 Oktober 2019). Paper cup coffee, menawarkan fasilitas ruangan indoor lantai 1 dan outdoor di lantai 2 dengan tema garden. Tempat parkir cukup, dan tema café yang diusung adalah minimalis modern. Historica, fasilitas ruangan indoor dan outdoo, music in store, ruang berkonsep klasik industrial dengan menggunakan interor yang membangun unsur vintage dengan dekorasi unik disetiap ruangan dan beberapa property pendukung bertema kayu. Excelso, mempunyai fasilitas indoor di dalam mall. Terdapat music in store, smoking area, pencahayaan cukup, konsep modern dengan interior serba nuansa kayu.

Berdasarkan dari konsep yang diusung, pada cabang baru di Kayoon, Rolag Kopi ingin memberikan suasana berbeda dengan membangun store atmosphere yang nyaman. Rolag Kopi berusaha menarik pelanggan menjadikan hangout in café sebagai gaya hidup. Strategi tersebut dilakukan agar konsumen terutama generasi muda penikmat kopi berkunjung dan merasa nyaman berada di gerainya dengan menyediakan ruangan indoor, penataan café yang lebih tepat dengan berbagai fasilitas pendukung lainnya. Dari penataan atmosfer Rolag Kopi Kayoon berkonsep modern minimalis dengan tampilan bangunan yang menyerupai stasiun kereta api sehingga berbeda dari café lainnya (Hasil wawancara dengan manajer Rolag Kopi Kayoon pada 14 November 2019).

Namun sepertinya hal tersebut dirasa belum cukup untuk meningkatkan konsumen untuk berkunjung, dikarenakan jumlah pengunjung terus mengalami fluktuasi selama lima bulan terakhir. Pada bulan September dan Oktober jumlah pengunjung café mengalami penurunan paling banyak selama lima bulan terakhir di tahun 2019, dari hasil wawancara dengan manajer Rolag Kopi Kayoon pada (9 Desember 2019). Hal ini menggambarkan jika ketatnya persangian yang membuat konsumen bisa saja beralih ke café lainnya, terlebih adanya brand café yang sudah lebih dulu muncul seperti Excelso, Starbuck, Coffee Toffee, Historica café dan lainnya. Sementara trend hangout in café sedang tumbuh dikalangan masyarakat, bahkan Rolag Kopi Kayoon telah melakukan pengembangan dan menambah beberapa interior, spot foto, serta fasilitas yang dibutuhkan konsumen. Tampilan layout dibuat menarik dan menjaga kebersihan gerai, berbagai upaya dilakukan untuk memberikan kesan menarik sehingga mampu mendorong terciptanya keputusan pembelian konsumen.

Rolag Kopi Kayoon telah membangun store atmosphere yang nyaman dan unik dengan mendesain cafenya dengan konsep industrial minimalis yang menyerupai stasiun kereta api dengan tujuan menarik lebih banyak konsumen untuk berkunjung, terlebih gaya hidup hedonis masyarakat kota dengan menghabiskan waktunya di luar rumah dengan mengunjungi café-café sebagai tempat nongkrong menjadi peluang yang besar bagi Rolag Kopi Kayoon, namun pada 2019, lima bulan terakhir Rolag Kopi Kayoon mengalami penurunan pengunjung pada bulan September dan Oktober. Kondisi ini yang menjadi kontradiksi fenomena gap dalam penelitian ini.

Penelitian ini bertujuan untuk menganalisis dan membahas pengaruh store atmosphere dan gaya hidup hedonis terhadap keputusan pembelian pada konsumen Rolag Kopi Kayoon Surabaya).

\section{KAJIAN PUSTAKA DAN PENGEMBANGAN HIPOTESIS}

\section{Keputusan Pembelian}

Menurut Setiadi (2008:332), keputusan pembelian adalah suatu proses pengintegrasian yang menggabungkan pengetahuan konsumen untuk mengevaluasi beberapa pilihan alternatif dan mengakhirnya dengan memilih salah satu di antaranya. Sedangkan Schiffman dan Kanuk (2010) dalam Sumarwan (2011:357) mendefinisikan suatu keputusan sebagai proses pemilihan dari suatu tindakan dua atau lebih dari pilihan alternatif yang ada. Konsumen yang hendak menentukan pilihan 
Kartika Ayu Wulandari \& Sri Setyo Iriani. Store Atmosphere dan Gaya Hidup Hedonis sebagai Penentu Keputusan Pembelian (Studi pada Konsumen Rolag Kopi Kayoon Surabaya)

maka dihadapkan pada beberapa pilihan alternatif yang ditawarkan. Dari berbagai pilihan tersebut kemudian individu akan berada di tahap memutuskan untuk membeli produk yang ditawarkan pemasar. Variabel keputusan pembelian dapat diukur menggunakan teori menurut Kotler dan Keller (2009:178) dalam Ramadhanti (2017), yaitu pilihan produk, jumlah pembelian, waktu pembelian.

\section{Store Atmosphere}

Menurut Kotler dan Keller (2012), atmosfer atau suasana setiap toko mempunyai desain tata letak fisik sendiri yang akan memudahkan ataupun menyulitkan konsumen untuk berputar-putar dalam gerai. Suasana toko harus bisa menciptakan suasana yang sesuai dengan pasar sasarannya agar dapat menarik konsumen untuk melakukan pembelian di toko tersebut. Sementara menurut Utami (2006:238) atmosfir adalah desain lingkungan melalui komunikasi visual, pencahayaan, warna, musik, dan wewangian untuk merangsang emosional dan persepsi pelanggan sehingga pada akhirnya akan memengaruhi pelanggan dalam membeli produk. Gilbert dalam Foster (2008:61) menjelaskan bahwa atmosphere merupakan sebuah perubahan terhadap perancangan lingkungan pembelian atau gerai toko melalui pesan fisik yang menghasilkan efek emosional khusus, yang akan mendorong konsumen melakukan pembelian. Dalam penelitian ini, store atmosphere menggunakan indikator Berman dan Evans (2010), Ramadhanti (2017) dan Hussain dan Ali (2015), yang disesuaikan dengan objek penelitian, sehingga indikator dalam penelitian ini, yaitu eksterior, general interior, store layout dan interior display.

Penelitian yang dilakukan oleh Ramadhanti (2017), menyatakan bahwa adanya pengaruh signifikan store atmosphere terhadap keputusan pembelian konsumen café Excelso. Berdasarkan penelitian yang dilakukan oleh Vicky (2019), menyatakan bahwa store atmosphere berpengaruh signifikan terhadap keputusan pembelian pada café Calibre. Semakin menarik atmosfer yang disajikan maka konsumen akan betah dan nyaman berada di café, sehingga kemungkinan besar pembelian akan semakin meningkat. Dalam penelitian Feng Chuan Pan, et., al, (2008) mengatakan bahwa adanya pengaruh fasilitas dan atmosfir restoran dalam memengaruhi emosi konsumen dalam keputusan pembelian. Dalam penelitian yang dilakukan oleh Morrison., et, al, (2010) menyatakan bahwa volume musik dan kehadiran aroma toko, keduanya menghasilkan peningkatan tingkat kesenangan dan emosional yang akan memengaruhi perilaku berbelanja, uang yang dikeluarkan, serta tingkat kepuasan konsumen. Pengaruh emosional akan membuat konsumen lebih senang berlama-lama berada di toko, hal ini yang akan cenderung memengaruhi pembelian mereka. Menurut Mowen dan Minor (2002:139) dalam Diawan (2016) atmosfer toko memengaruhi emosi konsumen dalam berbelanja, yang kemudian akan mendorong konsumen untuk menambah atau mengurangi pembelian. Dampak atmosfir toko dapat menciptakan kesan yang membuat pembeli akan meningkatkan pembelian, atau seseorang yang cukup membeli atau tidak memiliki rencana untuk membeli menjadi berniat kembali ke toko untuk membeli di tempat tersebut.

H1: Terdapat pengaruh antara store atmosphere dan keputusan pembelian (studi pada konsumen Rolag Kopi Kayoon Surabaya).

\section{Gaya Hidup Hedonis}

Menurut Susianto (1993), bahwa gaya hidup hedonis adalah pola hidup yang mengarah kepada aktivitas seseorang untuk mencari kesenangan hidup, seperti cara mereka menghabiskan waktunya di luar rumah, lebih senang bermain, merasa nyaman berada di keramaian, sering membeli barang yang kurang diperlukan membuat senang dan selalu ingin menjadi pusat perhatian. Sementara menurut Utami (2012), mendefinisikan bahwa gaya hidup hedonis adalah kecenderungan konsumen terhadap budaya konsumtif yang menggunakan produk untuk memperoleh kesenangan-kesenangan duniawi atau pola hidup glamor yang berorientasi pada materi.

Menurut Subandy dalam Achmad Syaiful (2012:15) ada beberapa bentuk gaya hidup, di antaranya adalah gaya hidup mandiri, gaya hidup hedonis dan gaya hidup konsumtif. Dalam mengukur gaya hidup konsumen terdapat beberapa dimensi dalam bentuk AIO (aktivitas, minat dan opini) atau pengukuran konsep psikografik. Menurut Kasali (2003:242) menjelaskan bahwa ciri-ciri individu yang melakukan kegiatan hedonis adalah individu yang selalu menyelesaikan masalah bila mengalami 
kesulitan dengan keluar rumah yaitu dengan cara bermain. Seseorang yang memiliki gaya hidup hedonis memiliki kecenderungan perilaku yang implusif, mudah dibujuk secara emosional, dan cenderung irasional. Indikator untuk mengukur gaya hidup hedonis menurut penelitian Hafasnuddin, et, al, (2018) dan penelitian Wibawanto (2016) antara lain, yaitu aktivitas (activities), minat (interests) dan pendapat (opinion).

Indrawati (2015) menyatakan bahwa gaya hidup hedonis berpengaruh signifikan terhadap keputusan pembelian Jilbab Zoya. Wibawanto (2016) juga menyatakan bahwa gaya hidup hedonis yang terdiri dari aktivitas, minat dan opini berpengaruh signifikan terhadap shopping addiction. Artinya, aktivitas, minat, dan opini individu akan menciptakan suatu perilaku pembelian yang abnormal dan membuat seseorang mengeluarkan biaya dalam mendapatkan produk yang belum tentu sesuai dengan kebutuhannya, melainkan dikarenakan keinginan dan emosional dalam pengambilan keputusan pembeliannya.

H2: Terdapat pengaruh antara gaya hidup hedonis dan keputusan pembelian (studi pada konsumen Rolag Kopi Kayoon Surabaya).

\section{METODE PENELITIAN}

Penelitian ini menggunakan rancangan penelitian konklusif untuk menguji hipotesis dan menguji hubungan antar variabel (Malhotra, 2009). Penelitian ini termasuk ke dalam jenis penelitian kuantitatif dan menggunakan pendekatan kausal, dimana rancangan penelitian digunakan untuk mengetahui sebab akibat (Malhotra, 2009). Lokasi penelitian ditetapkan oleh peneliti di Rolag Kopi Kayoon Surabaya. Populasi penelitian adalah konsumen Rolag Kopi Kayoon yang berkunjung dan melakukan pembelian minimal 2 kali dengan minimal usia 17 tahun. Pengambilan sampel menggunakan teknik non probability sampling dengan menggunakan metode judgemental sampling yaitu konsumen Rolag Kopi Kayoon yang sesuai dengan karakteristik peneliti. Jumlah responden yang dalam penelitian ini sebanyak 110 responden yang sudah termasuk penambahan sampel $10 \%$ guna mengantisipasi adanya angket yang tidak memenuhi syarat.

Jenis dan sumber data penelitian berasal dari data primer dan data sekunder. Data primer didapatkan dengan menyebaran angket kepada responden. Data sekunder didapatkan dengan melakukan wawancara, literatur buku, artikel ilmiah, jurnal atau studi terdahulu, maupun berita yang berhubungan dengan variabel dan objek pada penelitian. Skala pengukuran yang digunakan adalah skala likert. Teknik pengumpulan data yaitu dengan menyebarkan angket secara langsung kepada konsumen Rolag Kopi Kayoon Surabaya.

\section{HASIL DAN PEMBAHASAN}

\section{Deskripsi Responden}

Dalam penelitian ini karakteristik responden didasarkan pada demografi jenis kelamin, pekerjaan, usia, dan pendapatan pada konsumen Rolag Kopi Kayoon Surabaya. Hasil penelitian menunjukkan bahwa mayoritas responden adalah berjenis kelamin laki-laki sebanyak $64(58,2 \%)$, dan 41,8\% adalah berjenis kelamin perempuan dengan jumlah sebanyak 46 responden. Responden mayoritas rentang usia antara 17-22 tahun dengan jumlah sebanyak 45 responden (40,9\%), sebanyak 39 responden (35,5\%) denganusia 23-28 tahun, sebanyak 22 responden (20,0\%) di antaranya berusia 29-34 tahun dan sebanyak 4 responden $(3,6 \%)$ dengan usia lebih dari 35 tahun. Hasil tersebut memberikan informasi bahwa sebagian besar responden memiliki usia 17-22 tahun.

Dari hasil karakteristik pekerjaan terbanyak responden yaitu pelajar/ mahasiswa dengan jumlah 37 responden $(33,6 \%)$, pegawai swasta sebanyak 34 responden $(30,9 \%)$, wiraswasta sebanyak 20 responden $(18,2 \%)$, kemudian responden yang memiliki pekerjaan lainnya sebanyak 12 responden $(10,9 \%)$, dan sebanyak 7 responden $(6,4 \%)$ di antaranya adalah bekerja sebagai PNS. Hasil menunjukkan sebagian besar responden adalah pelajar/ mahasiswa. Serta mayoritas jumlah 
Kartika Ayu Wulandari \& Sri Setyo Iriani. Store Atmosphere dan Gaya Hidup Hedonis sebagai Penentu Keputusan Pembelian (Studi pada Konsumen Rolag Kopi Kayoon Surabaya)

pengeluaran dalam 1 bulan yang dilakukan oleh responden adalah sekitar Rp2.000.000-Rp2.999.999 dengan jumlah 31 responden $(28,2 \%)$. Setelah memperoleh hasil uji asumsi klasik dan semua asumsi terbebas, selanjutnya adalah melakukan uji analisis regresi linear berganda pada variabel store atmosphere dan gaya hidup hedonis terhadap keputusan pembelian.

\section{Hasil Uji Validitas dan Reliabilitas}

Uji validitas dilakukan dengan cara menyebar angket kepada 30 responden terlebih dahulu untuk mengetahui kevalidan dari masing-masing pernyataan. Berdasarkan tabel 1, diketahui bahwa keseluruhan item-item pernyataan tersebut telah memiliki nilai corrected item-total correlation $\left(\mathrm{R}_{\text {hitung }}\right)>\mathrm{R}_{\text {tabel }}(0,361)$. Nilai tersebut menyatakan bahwa setiap pernyataan item dalam angket valid dan dapat digunakan untuk mengukur variabel store atmosphere $\left(\mathrm{X}_{1}\right)$ dan gaya hidup hedonis $\left(\mathrm{X}_{2}\right)$ dan keputusan pembelian (Y).

\section{Tabel 1}

HASIL UJI VALIDITAS

\begin{tabular}{|c|c|c|c|}
\hline Variabel & Item & Corrected Item-Total Correlation & Keterangan \\
\hline Store Atmosphere (X1) & $\begin{array}{l}\mathrm{X}_{1.1 .1} \\
\mathrm{X}_{1.1 .2} \\
\mathrm{X}_{1.1 .3} \\
\mathrm{X}_{1.1 .4} \\
\mathrm{X}_{1.1 .5} \\
\mathrm{X}_{1.2 .1} \\
\mathrm{X}_{1.2 .2} \\
\mathrm{X}_{1.2 .3} \\
\mathrm{X}_{1.2 .4} \\
\mathrm{X}_{1.3 .1} \\
\mathrm{X}_{1.3 .2} \\
\mathrm{X}_{1.3 .3} \\
\mathrm{X}_{1.4 .1} \\
\mathrm{X}_{1.4 .2} \\
\mathrm{X}_{1.4 .3}\end{array}$ & $\begin{array}{l}0,642 \\
0,662 \\
0,607 \\
0,604 \\
0,566 \\
0,625 \\
0,623 \\
0,638 \\
0,638 \\
0,594 \\
0,640 \\
0,610 \\
0,624 \\
0,675 \\
0,604\end{array}$ & Valid \\
\hline $\begin{array}{l}\text { Gaya HidupHedonis } \\
\text { (X2) }\end{array}$ & $\begin{array}{l}\mathrm{X}_{2.1 .1} \\
\mathrm{X}_{2.1 .2} \\
\mathrm{X}_{2.1 .3} \\
\mathrm{X}_{2.1 .4} \\
\mathrm{X}_{2.2 .1} \\
\mathrm{X}_{2.2 .2} \\
\mathrm{X}_{2.2 .3} \\
\mathrm{X}_{2.2 .4} \\
\mathrm{X}_{2.3 .1} \\
\mathrm{X}_{2.3 .2} \\
\mathrm{X}_{2.3 .3}\end{array}$ & $\begin{array}{l}0,600 \\
0,587 \\
0,571 \\
0,666 \\
0,643 \\
0,561 \\
0,561 \\
0,550 \\
0,603 \\
0,636 \\
0,728\end{array}$ & Valid \\
\hline $\begin{array}{l}\text { Keputusan Pembelian } \\
\text { (Y1) }\end{array}$ & $\begin{array}{l}\mathrm{Y}_{1.1 .1} \\
\mathrm{Y}_{1.1 .2} \\
\mathrm{Y}_{1.1 .3} \\
\mathrm{Y}_{1.2 .1} \\
\mathrm{Y}_{1.2 .2} \\
\mathrm{Y}_{1.3 .2} \\
\mathrm{Y}_{1.3 .2}\end{array}$ & $\begin{array}{l}0,655 \\
0,746 \\
0,685 \\
0,682 \\
0,712 \\
0,663 \\
0,704\end{array}$ & Valid \\
\hline
\end{tabular}

Sumber: Data diolah

Hasil uji reliabilitas dari angket yang telah disebarkan pada 30 responden menyatakan bahwa hasil Cronbach's alpha di atas 0,70, sehingga angket pada penelitian ini dinyatakan reliable dan dapat dilanjutkan pada tahap selanjutnya. 


\section{Tabel 2}

HASIL UJI RELIABILITAS

\begin{tabular}{lccc}
\hline \multicolumn{1}{c}{ Variabel } & Cronbach' s Alpha & Cut-Off Value & Keterangan \\
\hline Store Atmosphere & 0,882 & & Reliabel \\
Gaya Hidup Hedonis & 0,820 & 0,70 & Reliabel \\
Keputusan Pembelian & 0,813 & & Reliabel \\
\hline
\end{tabular}

Sumber : Data diolah

\section{Uji Normalitas}

Uji normalitas bertujuan untuk menguji regresi dari variabel pengganggu atau residual apakah memiliki distribusi normal agar data bisa digunakan dalam uji $\mathrm{F}$ dan uji $\mathrm{t}$, jika asumsi ini dilanggar maka uji statistik menjadi tidak valid untuk menguji normalitas. Hasil penelitian membuktikan bahwa besar nilai signifikansi Kolmogorov-Smirnov lebih besar dari 0,05 yaitu 0,200, sehingga residual model regresi berdistribusi normal.

\section{Uji Multikolinieritas dan Uji Heterokedastisitas}

Hasil uji multikolinieritas nilai tolerance dua variable yakni $0,981>0.10$ menunjukkan tidak adanya multikoleniaritas antara variabel bebas, dan nilai VIF kedua variabel adalah $1,019<10$ sehingga tidak terjadi multikoleniaritas antar variabel bebas. Hasil Uji Heterokedastisitas diketahui bahwa semua variabel bebas memiliki nilai signifikan lebih dari 0,05 yaitu nilai signifkan variabel store atmosphere adalah 0,605 dan variabel gaya hidup hedonis adalah 0,493. Sehingga, model regresi dalam penelitian ini tidak terjadi heterokedastisitas.

\section{Uji Regresi Linear Berganda}

Nilai konstanta $(\alpha)$ pada penelitian ini sebesar -2.265 menyatakan bahwa jika store atmosphere dan gaya hidup hedonis sama dengan nilai 0, maka nilai keputusan pembelian konsumen Rolag Kopi sebesar -2.265. Sehingga, variabel independen tidak sepenuhnya memengaruhi keputusan pembelian, sehingga keputusan pembelian dapat tetap terjadi dengan dipengaruhi oleh variabel lainnya. Nilai koefisien untuk variabel store atmosphere adalah sebesar 0,358. Tanda positif pada koefisien regresi menunjukkan bahwa store atmosphere dan keputusan pembelian memiliki pengaruh positif. Semakin baik pelaku bisnis membangun store atmosphere maka akan semakin tinggi keputusan pembelian terhadap café Rolag Kopi Kayoon. Nilai koefisien untuk variabel gaya hidup hedonis adalah sebesar 0,203 . Tanda positif pada koefisien regresi menunjukkan bahwa gaya hidup hedonis dan keputusan pembelian memiliki pengaruh positif. Artinya semakin besar gaya hidup hedonis seseorang, maka semakin besar pula keputusan pembelian konsumen terhadap café Rolag Kopi Kayoon. Sehingga terdapat hubungan antara gaya hidup hedonis terhadap keputusan pembelian. Dari hasil analisis regresi pada tabel 3 di atas, maka dapat diperoleh persamaan regresi linier berganda (1).

$\mathrm{Y}=-2.265+0,358 \mathrm{X} 1+0,203 \mathrm{X} 2+\mathrm{e}$

\section{Tabel 3 \\ HASIL ANALISIS REGRESI LINIER BERGANDA}

\begin{tabular}{|c|c|c|c|c|c|}
\hline \multirow{2}{*}{ Model } & \multicolumn{2}{|c|}{$\begin{array}{l}\text { Unstandardized } \\
\text { Coefficients }\end{array}$} & \multirow{2}{*}{$\begin{array}{c}\text { Standardized } \\
\text { Coefficients } \\
\text { Beta }\end{array}$} & \multirow[t]{2}{*}{$\mathbf{t}$} & \multirow{2}{*}{ Sig. } \\
\hline & B & Std. Error & & & \\
\hline (Constant) & -2.265 & 5.313 & & -.426 & .671 \\
\hline Store Atmosphere $\left(\mathrm{X}_{1}\right)$ & .358 & .069 & 446 & 5.180 & .000 \\
\hline Gaya Hidup Hedonis $\left(\mathrm{X}_{2}\right)$ & .203 & .078 & .224 & 2.602 & .011 \\
\hline
\end{tabular}

Sumber: Data diolah (2020)

Nilai koefisien determinasi menunjukkan besarnya kontribusi variabel bebas store atmosphere $\left(\mathrm{X}_{1}\right)$ dan gaya hidup hedonis $\left(\mathrm{X}_{2}\right)$ terhadap variabel terikat keputusan pembelian $(\mathrm{Y})$. Hasil nilai koefisien 
Kartika Ayu Wulandari \& Sri Setyo Iriani. Store Atmosphere dan Gaya Hidup Hedonis sebagai Penentu Keputusan Pembelian (Studi pada Konsumen Rolag Kopi Kayoon Surabaya)

determinasi nilai Adjusted $\mathrm{R}$ Square sebesar 0,207= 20,7\%. Berdasarkan nilai tersebut, store atmosphere $\left(\mathrm{X}_{1}\right)$ dan gaya hidup hedonis $\left(\mathrm{X}_{2}\right)$ memengaruhi keputusan pembelian konsumen terhadap Rolag Kopi Kayoon sebanyak 20,7\%. Sedangkan presentase sisanya sebesar 0,793 = 79,3\% dipengaruhi oleh variabel lain diluar variabel yang digunakan dalam penelitian ini.

Tabel 3 juga menunjukkan nilai thitung untuk variabel store atmosphere sebesar 5,180 lebih besar dari $\mathrm{t}_{\text {tabel }}(1,982)$ maka Ho di tolak dan Ha diterima. Sehingga dapat dikatakan bahwa variabel store atmosphere $\left(\mathrm{X}_{1}\right)$ mempunyai pengaruh yang signifikan terhadap keputusan pembelian (Y). Nilai thitung untuk variabel gaya hidup hedonis sebesar 2,602 lebih besar dari tabel $(1,982)$ maka Ho ditolak dan Ha diterima. Sehingga dapat dikatakan bahwa variabel store atmosphere dan gaya hidup hedonis berpengaruh signifikan terhadap keputusan pembelian, dengan variabel store atmosphere yang memiliki pengaruh paling besar.

\section{Pengaruh Store Atmosphere terhadap Keputusan Pembelian}

Variabel store atmosphere berpengaruh signifikan dan positif terhadap keputusan pembelian pada Rolag Kopi Kayoon Surabaya. Sehingga dapat diartikan bahwa semakin tinggi store atmosphere yang dibangun maka akan semakin tinggi pula tingkat keputusan pembelian pada konsumen Rolag Kopi Kayoon Surabaya, dan hipotesis pertama terbukti kebenarannya.

Hasil penelitian ini membuktikan teori menurut Utami (2012) store atmosphere merupakan rancangan lingkungan yang diciptakan oleh pelaku bisnis ritel untuk merangsang emosional dan persepsi konsumen sehingga akan memengaruhi perilaku pembelian konsumen. Sementara menurut Foster (2008:61) menjelaskan store atmosphere merupakan kombinasi pesan secara fisik melalui visual, musik, warna, dan bau yang direncanakan untuk membuat konsumen merasa nyaman berada di gerai. Store atmosphere sendiri dapat diilustrasikan sebagai perubahan perencanaan lingkungan pembelian yang mengkombinasi komponen perangsang secara fisik untuk menghasilkan efek emosional khusus, sehingga dapat memengaruhi konsumen dalam melakukan tindakan pembelian.

Berdasarkan jawaban responden pada indikator interior display dengan item pernyataan "Dekorasi ruangan yang diciptakan Rolag Kopi sesuai dengan tema stasiun kereta api yang unik" memiliki nilai paling tinggi. Hasil ini menunjukkan bahwa pemilihan dekorasi pada Rolag Kopi Kayoon dengan konsep menyerupai stasiun kereta api berhasil membangkitkan suasana toko yang sesuai tema yang ingin diciptakan. Keunikan bangunan dan konsep dari Rolag Kopi Kayoon yang ditambah dengan lokasi yang berada di samping sungai memberikan kesan berbeda kepada pelanggan yang berkunjung, suasana nyaman yang diciptakan menjadi nilai lebih. Konsep stasiun kereta api menjadi daya tarik yang khas bagi Rolag Kopi Kayoon. Dekorasi interior yang digunakan oleh Rolag Kopi semirip mungkin dengan interior yang ada di stasiun, seperti tempat kasir yang menyerupai loket, kursi-kursi yang ditata seperti kursi tunggu di stasiun serta nuansa yang di café sebaik mungkin memberikan kesan yang nyata. Semakin baik dan menarik penataan pajangan dan dekorasi dalam toko, hal tersebut akan dapat meningkatkan emosi pengunjung. Keunikan konsep inilah yang akan merangsang pengunjung untuk melakukan keputusan pembelian.

Selain itu, Rolag Kopi juga selalu memberikan penyajian informasi yang jelas, melalui pajanganpajangan di toko, seperti papan menu, poster promosi dan interior lainnya. Terdapat banyak pilihan kursi seperti kursi dari kayu, sofa hingga kursi biasa yang bisa digunakan pengunjung. Rolag Kopi juga menyediakan ruangan indoor dan outdoor. Fasilitas lainnya pun disediakan seperti toilet, mushola dan area parkir untuk menunjang kenyaman konsumen yang berada di Rolag Kopi. Hasil penelitian ini membuktikan teori yang dikemukakan oleh Berman dan Evans (2010:463), setiap jenis interior display menyediakan sebuah infromasi pada pelanggan, menambah suasana dalamtoko dan melayani promosi, dimana tujuan utamanya adalah meningkatkan penjualan dan laba toko tersebut. Hasil penelitian ini mendukung oleh penelitian yang dilakukan Dessyana (2013) yang diperoleh hasil bahwa variabel interior display memengaruhi keputusan pembelian $(\mathrm{Y})$ secara signifikan. Dalam penelitian Feng Chuan Pan, et al, (2008) mengatakan bahwa adanya pengaruh fasilitas dan atmosfir restoran dalam memengaruhi emosi konsumen dalam keputusan pembelian. Gnanasundari (2014) menyatakan bahwa lingkungan dalam toko yang mencakup desain seperti dekorasi, suara, udara dan 
pajangan produk serta komponen lainnya yang berada di sebuah toko dapat memengaruhi perilaku pembelian konsumen.

Pada indikator general interior dengan item pernyataan "Pemutaran musik yang ada membuat saya lebih menikmati suasana di Rolag Kopi $\left(\mathrm{X}_{1.2 .3}\right)$ ". Hal ini menunjukkan bahwa musik yang diputar pada café telah berhasil merangsang pengunjung tetap berada di toko sehingga memberikan rasa nyaman untuk melakukan pembelian yang lebih. Tempo dan volume musik dapat memengaruhi perasaan konsumen dalam berbelanja. Rolag Kopi Kayoon selalu memutar musik paling update dan sedang populer, sehingga konsumen merasa senang berada di toko. Melalui musik, emosi konsumen akan terbentuk dan menimbulkan perasaan senang saat melakukan pembelian.

Pada indikator store layout dengan item pernyataan "Penataan jarak meja dan kursi tersusun baik memberi ruang gerak untuk pengunjung berlalu lalang di café $\left(\mathrm{X}_{1.3 .1}\right)$ ". Hal ini menunjukkan bahwa penataan meja dan kursi pada ruangan indoor dan outdoor yang mengikuti hilir sungai mempermudah pengunjung untuk mengakses setiap ruangan di Rolag Kopi. Penataan store layout dapat memengaruhi pengunjung dalam berbelanja pada toko retail. Pada indikator exterior dengan item pernyataan "Pintu masuk Rolag Kopi memudahkan akses pengunjung untuk keluar masuk $\left(\mathrm{X}_{1.1 .3}\right)$. Hal ini menunjukkan bahwa pintu masuk di Rolag Kopi Kayoon dinilai memiliki akses yang mudah. Lokasi café tidak jauh dari jalan raya dan pintu masuk utama café sangat luas, karena ruangan dibagi menjadi dua yaitu outdoor dan indoor, konsumen dengan leluasa keluar masuk café. Konsumen juga tidak akan kesulitan untuk mencari lokasi café yang berada dekat dengan jalan raya.

Dikaitkan dengan crosstabs karakteristik responden, maka responden yang paling mendominasi yaitu berjenis kelamin laki-laki dengan usia antara 17-22 tahun dan melakukan pengeluran rata-rata sebesar $<$ Rp. 1.000.000 per satu bulan terakhir, serta dengan status pelajar/ mahasiswa yang paling sering datang berkunjung. Berdasarkan survei dan wawancara yang dilakukan terhadap responden, diketahui bahwa mereka cenderung sering nongkrong di café-café dibandingkan tempat lain, terlebih sekarang ini banyak responden yang lebih mempertimbangkan suasana dan tampilan café dimana mereka akan memilih café untuk nongkrong. Rolag Kopi sudah menyuguhkan suasana toko yang menyerupai stasiun kereta api tanpa mengesampingkan kenyaman serta lokasi yang dekat dengan kantor dan pusat perbelanjaan dengan vibe cozy karena lokasi berada di sekitar hilir sungai.

Store atmosphere yang disuguhkan oleh Rolag Kopi Kayoon memberikan pengalaman tersendiri dibandingkan dengan cabang Rolag Kopi yang lainnya, mulai dari suasana toko yang nyaman dan unik karena lokasi café berada di samping sungai dengan desain toko yang menyerupai stasiun kereta api menjadi daya tarik yang berbeda dari pesaingnya. Dekorasi yang digunakan dan tatanan layout café merangsang emosional konsumen untuk berkunjung dan menghabiskan waktunya lebih lama di café Rolag Kopi Kayoon. Hal tersebut juga didukung dengan tampilan, musik, pencahayaan toko menjadi faktor penting agar pengunjung melakukan pembelian di Rolag Kopi Kayoon.

\section{Pengaruh Gaya Hidup Hedonis terhadap Keputusan Pembelian}

Variabel gaya hidup hedonis berpengaruh signifikan dan positif terhadap keputusan pembelian pada Rolag Kopi Kayoon. Sehingga dapat diartikan bahwa semakin tinggi gaya hidup hedonis konsumen maka akan semakin tinggi juga tingkat keputusan pembelian pada konsumen Rolag Kopi Kayoon Surabaya, dan hipotesis kedua terbukti kebenarannya. Hal ini menunjukkan bahwa responden memiliki gaya hidup hedonis yang cukuptinggi. Konsumen Rolag Kopi Kayoon lebih senang menghabiskan waktu luangnya untuk berkunjung ke gerai dan mencari hal-hal yang menyenangkan dengan mengunjungi tempat hiburan. Konsumen merasa senang jika menghabiskan waktunya untuk berlama-lama tinggal di Rolag Kopi Kayoon berkumpul bersama kelompoknya, mencari hiburan dengan datang jika Rolag Kopi Kayoon mengadakan event-event tertentu. Beberapa konsumen juga mengatakan jika lebih senang menikmati secangkir kopi sambil mengobrol bersama temannya di café dibandingkan di rumah. Mereka menganggap jika kegiatan tersebut merupakan kebiasaan yang sudah biasa di masyarakat perkotaan. 
Kartika Ayu Wulandari \& Sri Setyo Iriani. Store Atmosphere dan Gaya Hidup Hedonis sebagai Penentu Keputusan Pembelian (Studi pada Konsumen Rolag Kopi Kayoon Surabaya)

Hasil tersebut didukung oleh teori menurut Setiadi (2010:77), gaya hidup didefinisikan sebagai pola hidup seseorang bagaimana menghabiskan waktu mereka (aktivitas), apa yang dianggap penting dalam lingkungannya (ketertarikan/ minat), dan apa yang mereka pikirkan tentang diri sendiri dan dunia sekitarnya (pendapat), gaya hidup umumnya merupakan bagian dari perilaku konsumen yang akan memengaruhi perilaku individu dalam melakukan pembelian. Menurut Munandar dalam Kelly (2015) menjelaskan bahwa gaya hidup hedonis adalah pola hidup yang mengarah kepada aktivitas seseorang untuk mencari kesenangan hidup. Aktivitas tersebut seperti mengabiskan waktu di luar rumah, selalu ingin menjadi pusat perhatian, senang dengan keramaian kota, dan senang membeli barang yang kurang diperlukan. Penelitian yang dilakukan (Chen et al., 2017) tentang hedonic values terhadap purchase intention melalui Social E-commerce, menyatakan jika terdapat efek dari nilai hedonis terhadap pembelian konsumen dan penggunaan berkelanjutan sangat kuat.

Berdasarkan jawaban responden pada indikator aktivitas dengan item pernyataan "Saya memilih berkumpul dan bersenang-senang bersama teman di Rolag Kopi $\left(\mathrm{X}_{2.1 .4}\right)$ " memiliki nilai paling tinggi. Hasil tersebut menunjukkan bahwa responden setuju jika aktivitas konsumen dapat memengaruhi keputusan pembelian seseorang, konsumen lebih sering berkumpul dan menghabiskan waktunya bersama kelompoknya dengan nongkrong di Rolag Kopi Kayoon. Aktivitas yang dilakukan tidak hanya sekedar menikmati kopi namun café menjadi wadah yang tepat untuk menjalin sosialisasi, konsumen lebih senang meluangkan waktunya untuk berkunjung di café lebih lama dibandingkan di rumah. Kemudian pada indikator Minat dengan item pernyataan "Saya tertarik mengunjungi Rolag Kopi karena dapat bertemu dengan orang-orang yang memiliki kesaamaan hobi $\left(\mathrm{X}_{2.2 .2}\right)$ ". Hal ini menunjukkan bahwa konsumen Rolag Kopi Kayoon memiliki ketertarikkan terhadap ngopi di café untuk bertemu dengan orang-orang yang memiliki hobi yang sama dengan mereka, seperti pecinta kopi, komunitas motor dan lainnya. Sedangkan pada indikator Opini dengan item pernyataan "Duduk meminum secangkir kopi di café memiliki nilai gengsi sendiri $\left(\mathrm{X}_{2.3 .2}\right)$ ". Hal ini menunjukkan bahwa konsumen yang sedang nongkrong di Rolag Kopi Kayoon merasakan memiliki nilai gengsi jika menikmati secangkir kopi di Rolag Kopi dibandingkan di warung kopi.

Peningkatan aktivitas masyarakat dalam melakukan perilaku berbelanja akan meningkatkan perilaku belanja yang abnormal (Wibawanto, 2016). Penelitian ini menunjukkan gaya hidup hedonis konsumen Rolag Kopi Kayoon saat ini café telah beralih fungsi, tidak hanya sebagai tempat menikmati secangkir kopi melainkan lebih sebagai tempat untuk melakukan berbagai kegiatan sosialisasi, seperti banyaknya remaja yang nongkrong menghabiskan waktunya di café, bukan sekedar hiburan atau rekreasi melainkan menjadi sebuah gaya hidup remaja. Tujuan beberapa kalangan mengunjungi café sebagai tempat favorit untuk berkumpul bersama teman sekelompoknya, menghilangkan penat dengan mengobrol hingga berjam-jam bersama teman, tempat menjalin koneksi dengan orang baru atau kegiatan komunitas dan lainnya. Pengunjung datang dikarenakan menginginkan kenyamana yang tidak didapatkan di restoran ataupun tempat lainnya.

\section{KESIMPULAN}

Berdasarkan hasil analisis data dan pembahasan dari penelitian yang dilakukan, maka dapat disimpulkan bahwa terdapat pengaruh yang positif yang signifikan antara store atmosphere dan gaya hidup hedonis terhadap keputusan pembelian (Studi pada konsumen Rolag Kopi Kayoon Surabaya). Berdasarkan hasil penelitian variabel store atmosphere dan gaya hidup hedonis berpengaruh terhadap keputusan pembelian konsumen pada Rolag Kopi Kayoon Surabaya. Selain itu, keterbatasan dalam penelitian ini adalah hanya meneliti responden Rolag Kopi Kayoon Surabaya, penelitian berikutnya dapat memperluas dengan penelitian pada semua cabang Rolag Kopi yang berada di Surabaya. Sehingga informasi yang dapat diperoleh akan lebih beragam. Penelitian ini terbatas menggunakan angket tertutup, diharapkan peneliti berikutnya dapat menggunakan angket terbuka, sehingga dapat mengeksplore jawaban dari responden secara detail. Penelitian selanjutnya dapat melibatkan variabelvariabel lain, yaitu variabel harga, lokasi, kualitas pelayanan, kemudahan, promo, kualitas produk dan niat berkunjung kembali sebagai variabel dependen. 


\section{DAFTAR PUSTAKA}

Berman, Barry, dan Joel R Evans. 2010. Retail Management, A Strategic Approach. 11th Edition. United State of American: Pearson Education, Inc.

Chen, W.-K., Chang, D.-S., \& Chen, C.-C. (2017). The Role of Utilitarian and Hedonic Values on Users' Continued Usage and Purchase Intention in a Social Commerce Environment. Journal of Economics and Management, 13(2), 193-220. https://doi.org/10.1016/j.ijhm.2016.06.007

Chuan Pan, Jean Su, Chao Chiang.2008. Dual attractiveness ofwinery: atmospheric cues on purchasing. International Journal of Wine Business Reasearch (Online), Vol.20. No.2 : 95-110.

Dessyana, Cindy. J. 2013. "Store Atmosphere Pengaruhnya Terhadap Keputusan Pembelian Konsumen Di Texas Chicken Multimart Ii Manado.” EMBA 1(3): 844-52.

Diawan, Nizar Satya. 2016. "The Influence Of Store Atmosphere On Purchase Decision And Customer Satisfaction ( Case study on Indomaret Customers JL . Raya TlogomasNo .37 , Malang ).” Jurnal Administrasi Bisnis (JAB) 30(37): 8-16.

Engel, James F., Roger D. Blackwell, dan Paul W. Miniard. 2001. Perilaku Konsumen. Jilid 2.Jakarta: Binarupa Aksara.

Foster, Bob. 2008. Manajemen Ritel. Bandung: Alfabeta.

Ghozali, Imam. 2016. Aplikasi Analisis Multivariate dengan Program IBM SPSS 21 :Update PLS Regresi.Semarang.Badan PenerbitUniversitasDiponegoro.

Gnanasundari, Rampraba\& Justus, Frank Sunil .T. 2014. "In- store influence on purchaser in jewelry buying process." Vishwakarma Business Review.

Hafasnuddin, Ridwan, dan Muslim A. Djalil. 2018. The Coffee Shop Lifestyle in Banda Aceh City, Indonesia: A Study Based on Marketing Approach. Atlantis Press. Volume 292. https://doi.org/10.2991/agc-18.2019.46

Hidayat, Taufik, Achmad Fauzi, dan Inggang Perwangsa Nuralam. 2018. Pengaruh Store Atmosphere (SuasanaToko) Terhadap Keputusan Pembelian( Survei pada Konsumen Distribution Store Inspired27 Kota Malang ). Administrasi Bisnis. 60(1): 46-55.

Hussain, Riaz, dan Mazhar Ali. 2015. "Effect of Store Atmosphere on Consumer Purchase Intention." International Journal of Marketing Studies. Volume 7(2).http://dx.doi.org/10.5539/ijms.v7n2p35

Indrawati, Devi. 2015. Pengaruh Citra Merek Dan Gaya Hidup Hedonis Terhadap Keputusan Pembelian Jilbab 'Zoya'. Jurnal Riset Ekonomi dan Manajemen. Volume 15, No. 2. http://dx.doi.org/10.17970/jrem.15.150207.ID

Kasali, Rhenaldi. 2001. Membidik Pasar Indonesia :Segmentasi, Targeting, and Positioning. Jakarta; Gramedia Pustaka Utama.

Kotler, Philip dan Amstrong Gary. 2008. Prinsip-prinsip Pemasaran. Edisi 12. Bahasa Indonesia. Jilid 1. Jakarta :Erlangga.

Kotler, P dan Keller K. 2012. Manajemen Pemasaran. Edisi 12. Erlangga, Jakarta.

Ma'ruf, Hendi. 2005. Pemasaran Ritel. Jakarta: Gramedia Pustaka Utama. 
Kartika Ayu Wulandari \& Sri Setyo Iriani. Store Atmosphere dan Gaya Hidup Hedonis sebagai Penentu Keputusan Pembelian (Studi pada Konsumen Rolag Kopi Kayoon Surabaya)

Malhotra, N. K. 2009. Riset Pemasaran. Edisi keempat. Vol. 1. Indonesia: PT. Indeks.

Morrison, Michael, Sarah Gan, Chris Dubelaar, dan Harmen Oppewal. 2011. "In-store music and aroma influences on shopper behavior and satisfaction." Journal of Business Research.

Mowen, John C., dan Minor, Michael. 2002. Perilaku Konsumen. Edisi 5. Jilid 1. Jakarta: Erlangga.

Peni, Widarti. 2019. Pertumbuhan Kafe \& Restoran di Surabaya Dongkrak Pendapatan Daerah. Surabaya.Bisnis.com. (https://surabaya.bisnis.com/read/20190613/532/933444/pertumbuhankafe-restoran-di-surabaya-dongkrak-pendapatan-daerah, diakses 24 Oktober 2019).

Purnomo, Albert Kurniawan. 2017. Pengaruh Cafe Atmosphere terhadap Keputusan Pembelian Gen Y pada Old Bens Cafe.JurnalManajemen Maranatha. 16(2): 133.https://doi.org/10.28932/jmm.v16i2.384

Ramadhanti, Sufie Halala. 2017. Pengaruh Store Atmosphere Dan Harga Terhadap Keputusan Pembelian (Studi Pada Konsumen Excelso Jalan Sulawesi No. 71 Surabaya). Jurnal Ilmu Manajemen (JIM) 5(1): 1-7.

Rinandiyana, Lucky Radi, Deasy Lestary Kusnandar, dan Beben Bahren. 2018. Literasi Ict Dan Perilaku Hedonist Dalam Memilih Tempat Wisata Di Kalangan Kelas Menengah Sebagai Pengaruh Gaya Hidup. Sustainable Competitive Advantage (SCA). 1-13. http://jp.feb.unsoed.ac.id/index.php/sca-1/article/view/1202

Setiadi, Nugroho J. 2010. Perilaku Konsumen. Jakarta: Prenada Media.

Selvi, dan Lestari Ningrum. 2020. "Gaya Hidup Minum Kopi Dalam Pengambilan Keputusan Pembelian Kopi (Studi Kasus Pada Kopi Kenangan Gandaria City - Jakarta)." Ilmiah Kepariwisataan. http://ejournal.stipram.ac.id/index.php/kepariwisataan/article/view/124.

Sugiyono. 2010. Metode Penelitian Pendidikan Pendekatan Kuantitatif, kualitatif, dan R\&D. Bandung: Alfabeta.

Sumarwan, Ujang. 2011. Perilaku Konsumen Teori Penerapannya dalam Pemasaran. EdisiKedu. Bogor: Ghalia Indonesia.

Susanto, Angga Sandy. 2013. Membuat Segmentasi Berdasarkan Life Style (Gaya Hidup). Jibeka 7: $1-6$.

Susanto, B.A. 2001. Potret-Potret Gaya Hidup Metropolis. Jakarta: Kompas.

Utami, Novia Widya. 2018. Strategi Pemasaran Bisnis Kafe yang Paling Efektif untuk Anda Lakukan. Jurnal.id. (https://www.jurnal.id/id/blog/strategi-pemasaran-bisnis-kafe-yang-paling-efektifuntuk-anda-lakukan/, diakses pada 26 Oktober 2019)

Utami, Christina Whidya. 2012. Jakarta: Salemba Empat. Manajemen Ritel Strategi Dan Implementasi Ritel Modern.

Utami, Christina Widya. 2010. Manajemen Ritel. 2 ed. Jakarta: Salemba Empat.

Vicky. 2019. Pengaruh Food Quality, Brand Image, Store Atmosphere Terhadap Purchase Decision Pada Cafe Calibre. AGORA 7(2). http://publication.petra.ac.id/index.php/manajemenbisnis/article/view/9574.

Wibawanto, Sigit. 2016. Gaya Hidup Hedonisme Terhadap Perilaku Pembelian Di Pasar Modern (Studi Pada Masyarakat Kabupaten Kebumen). Fokus Bisnis 15(01): 54-71. 